\title{
SEEPAGE FLOW IN A BREAKER ZONE
}

\author{
Taro Kakinuma ${ }^{1}$, Shizuka Ohishi ${ }^{2}$ and Kazuo Nakamura ${ }^{3}$
}

\begin{abstract}
Seepage velocities in several breaker zones were measured with dye for visualization. Pressure gauges were also installed to obtain pore water pressure. Three cases of different incident-wave periods were treated in laboratory experiments. The time-averaged pore water pressure was higher near the shoreline, resulting in the seepage flow, the maximum velocity of which was larger as the incident-wave period was longer, generally moving from onshore to offshore. The penetrated water flowed out from the permeable seabed at a bar top or on the rather offshore side of the bar top if a bar was developed remarkably. The pore water pressure in the breaker zone showed time variation depending on the wave phases including wave breaking and bore propagation. There was a phase when the pore water pressure was locally low below the bar.
\end{abstract}

Keywords: seepage flow; pore water pressure; bar; permeable beach; breaker zone

\section{INTRODUCTION}

When waves contribute to the exchange between pore water and seabed water at a permeable beach (e.g. Precht and Huettel, 2004), the production and consumption of oxygen in sediments of the seabed play an important role for the water quality and ecosystem in shallow water regions. In a breaker zone, the water motion inside a permeable layer is affected by the wave motion through the oscillatory flow over the seabed, wave run-up, wave set-up due to wave breaking, seabed scouring, etc., such that the seepage flow in a breaker zone should depend on external force varying during a wave period.

Seepage flows in beaches have been studied through various methods such as hydraulic experiment and numerical calculation. Inouchi et al. (1990) numerically simulated coastal groundwater with a freshwater-saltwater interface in tidal conditions. Mutsuda et al. (2001) performed visualization of seepage flows in a breaker zone, as well as measurement of pressure on the seabed, to study the effects of wave-breaking types on seepage flows. Cheong et al. (2002) visualized seepage flows in a tideland using a wave basin. Kudella and Oumeraci (2006) measured residual pore water pressure under wave loads beneath a caisson breakwater in a large-scale experiment. Ma et al. (2004) performed computation of seepage flows concerning the profile change of a permeable beach.

In the present study, in order to explain the fundamental characteristics of water motion at permeable beaches including pore water, seepage velocities in breaker zones were measured using dye for visualization. Photographs were taken automatically to evaluate time-averaged seepage velocity vectors by tracing colored pore water. Three cases of different incident-wave periods were treated in laboratory experiments. Pressure gauges were also installed below the seabed to obtain pore water pressure, which changed during each period of waves.

\section{WAVE BASIN AND INCIDENT-WAVE CONDITIONS}

A uniformly sloping beach, which consisted of Toyoura standard sands, was built in a wave basin as shown in Fig. 1, where the length and width of the wave basin were 13.0 and $0.4 \mathrm{~m}$, respectively. The beach slope $\beta$ was $1 / 8$ and the still water depth outside the beach was $0.22 \mathrm{~m}$.

The following three cases of different incident regular waves were treated:

Case A: $T=0.48 \mathrm{~s}$ and $H=3.7 \mathrm{~cm}$,

Case B: $T=0.83 \mathrm{~s}$ and $H=5.3 \mathrm{~cm}$,

Case C: $T=1.20 \mathrm{~s}$ and $H=3.0 \mathrm{~cm}$,

where $T$ and $H$ were period and height of incident waves, respectively. Case A, B, and $\mathrm{C}$ are also called the short-, intermediate-, and long-period-wave cases, respectively.

\footnotetext{
${ }^{1}$ Department of Ocean Civil Engineering, Kagoshima University, 1-21-40 Korimoto, Kagoshima, Kagoshima 8900065, Japan

${ }^{2}$ Heisei Construction Co., Ltd., 1540-1 Ohoka, Numazu, Shizuoka 410-0022, Japan

${ }^{3}$ Technical Section, Kagoshima University, 1-21-40 Korimoto, Kagoshima, Kagoshima 890-0065, Japan
} 


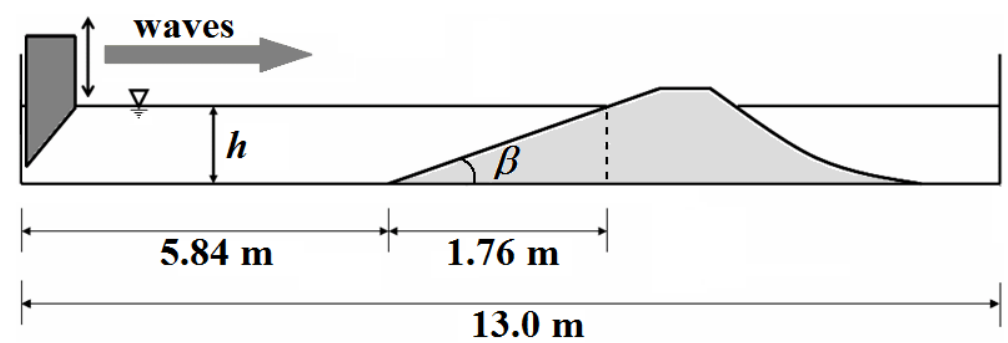

Figure 1. Schematic of wave basin.

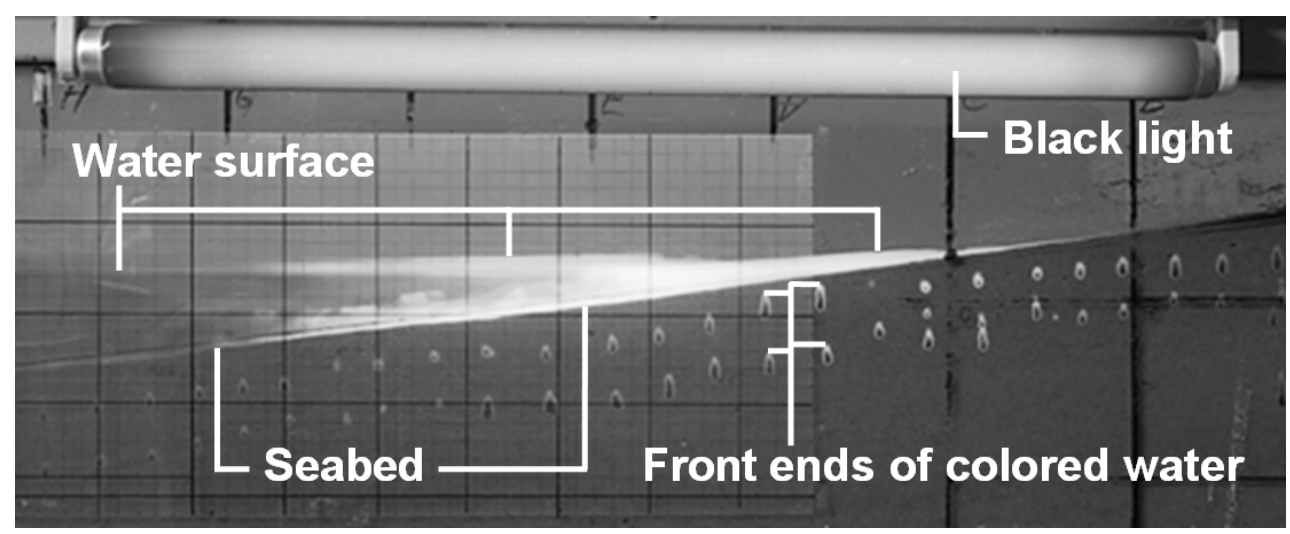

Figure 2. Visualization of a seepage flow. Colored pore water was illuminated with a black light.

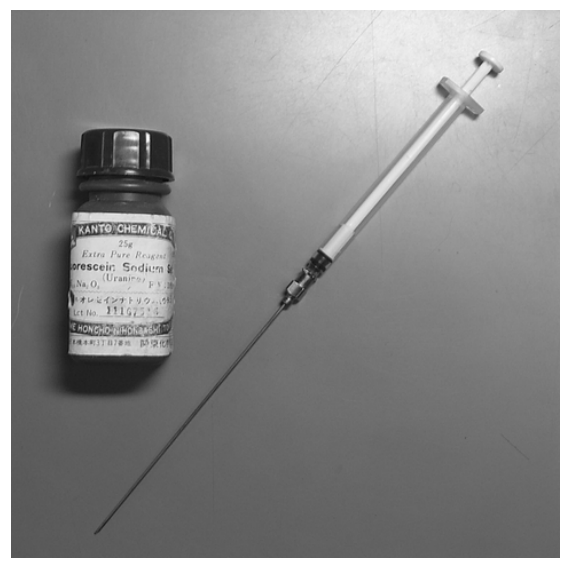

Figure 3. Ulanin, which was injected into sands using a syringe with a long needle.

\section{VISUALIZATION OF SEEPAGE FLOWS}

\section{Experimental Method}

The pore water inside the sand beach was partially dyed as shown in Fig. 2. The dye was Ulanin, which was injected into the sands along the glass wall using a syringe shown in Fig. 3. The number of colored points was around fifty in each case, where the initial diameter of colored points was about 3.0 $\mathrm{mm}$. It was confirmed that the sand particles were not colored. The colored pore water was illuminated with a black light to visualize seepage flows. Photographs were taken automatically every fifteen minutes. When the color of pore water was faded, the wave generator was stopped and the dye was added, after which the experiment was restarted. 
According to the photographs, time-averaged seepage velocity vectors were obtained by tracing the colored pore water in quasi steady conditions: if the colored pore water moved from point $P_{1}$ to point $P_{2}$ during a trace time between $t_{1}$ and $t_{2}$, a time-averaged seepage velocity vector during the time is determined by the arrow $\mathrm{P}_{1} \mathrm{P}_{2}$. If the dye showed diffusion, the front edge of each colored point was chased.

\section{Seepage Flows in Breaker Zones}

Experimental results of time-averaged seepage velocity vectors in Cases $\mathrm{A}, \mathrm{B}$, and $\mathrm{C}$ are shown in Figs. 4, 5, and 6, respectively, where seabed configurations at the start and finish times of tracing colored pore water are also drawn, as well as areas where the wave breaking occurred. The water levels shown in the figures are still water levels, where $z=0.0 \mathrm{~m}$. The seepage velocities depended on the period of incident waves, such that the trace time $\left(t_{2}-t_{1}\right)$ was different among the cases: $t_{2}-t_{1}=3,000$, 1,500 , and $150 \mathrm{~s}$ in Cases $\mathrm{A}, \mathrm{B}$, and $\mathrm{C}$, respectively.

According to Figs. 4 - 6, the pore water was disposed to move from onshore to offshore in all the cases.

In Case A, i.e., the short-period-wave case, the maximum value of seepage velocity was about $1.5 \times 10^{-5} \mathrm{~m} / \mathrm{s}$. The water penetrated into the permeable beach around where $0.8 \mathrm{~m} \leq X \leq 0.9 \mathrm{~m}$ as shown in Fig. 4, after which it changed its moving direction towards the top of the bar generated where $0.4 \mathrm{~m} \leq X \leq 0.5 \mathrm{~m}$; then the pore water flowed out near the bar top.

In Case B, where the period of incident waves was longer than that in Case A, the maximum value of seepage velocity was about $4.0 \times 10^{-5} \mathrm{~m} / \mathrm{s}$. Two bars were generated as shown in Fig. 5 . The water infiltrated into the permeable beach around where $0.9 \mathrm{~m} \leq X \leq 1.0 \mathrm{~m}$, as well as $0.25 \mathrm{~m} \leq X \leq 0.4 \mathrm{~m}$ between the two bars, after which the pore water flowed out near the bar tops or at just offshore sides of the bar tops.

In Case $\mathrm{C}$ of the longest incident-wave period, the maximum value of seepage velocity was about $3.0 \times 10^{-4} \mathrm{~m} / \mathrm{s}$, which was around twenty times as much as that in Case A. The water entered the permeable beach around where $0.9 \mathrm{~m} \leq X \leq 1.1 \mathrm{~m}$, after which it flowed out through a wider area where $0.45 \mathrm{~m} \leq X \leq 0.75 \mathrm{~m}$ for no bar was generated clearly.

It should be noted that, in Case $\mathrm{C}$, sand ripples were generated in the region where $X \leq 0.4 \mathrm{~m}$, in which the seepage flow could not follow the crests of sand ripples moving towards onshore as "sand waves' at a celerity between $7.3 \times 10^{-5}$ and $2.6 \times 10^{-4} \mathrm{~m} / \mathrm{s}$, such that the outflow points of pore water were not limited to near the crests of sand ripples. Incidentally, the number of sand ripples generated in Case $\mathrm{C}$ was more than ten.

\section{MEASUREMENT OF PORE WATER PRESSURE}

\section{Experimental Method}

Time variation of pore water pressure was measured at eight points indicated in Fig. 7 using fixed pressure gauges, i.e., KYOWA PGM- $02 \mathrm{KG}$, the rated capacity of which was about $20.0 \mathrm{kPa}$. At the centers of the notations (1) - (8) in Fig. 7, the pressure-gauge probe faces, which were covered with porous filters as shown in Fig. 8 to prevent the probe faces from touching sands directly, of Channels 1 - 8 were set upward, respectively. The measured displacement of pore water pressure head was amplified through a sensor interface, i.e., KYOWA PCD-300A, where the pore water pressure head was adjusted to $0.0 \mathrm{~m}$ in the still-water condition.

The elevation of the upper positions where the probe faces of Channels $1,3,5$, and 7 were set near the glass wall was about $6.0 \mathrm{~cm}$ below the still water level as shown in Fig. 9, while that of the lower positions where the probe faces of Channels 2, 4, 6, and 8 were installed was about $12.5 \mathrm{~cm}$ below the still water level; the distance between the centers of the probe faces at the lower positions and the interior face of the vertical glass wall was about $6.5 \mathrm{~cm}$.

\section{TIme-Averaged Pore Water Pressure in Breaker Zones}

Time-averaged pore water pressures during five minutes in Case A, B, and C are shown in Fig. 10. In the present paper, the pore water pressure is described by the displacement of the pore water pressure head from that in the still-water condition. 


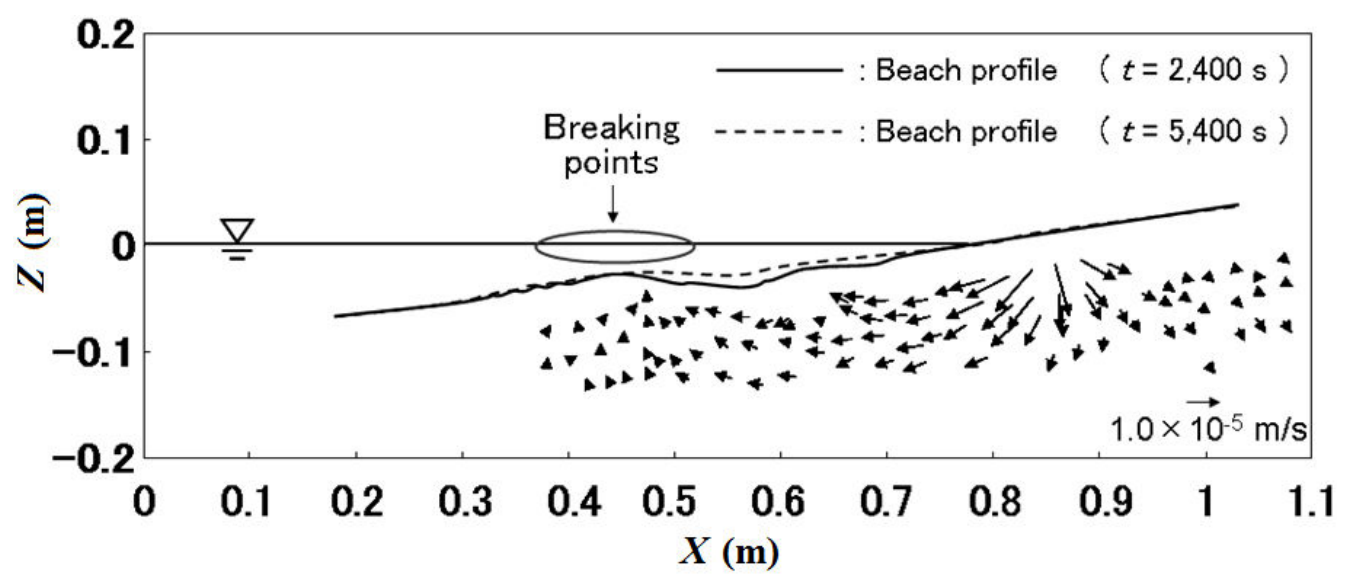

Figure 4. Seepage velocity vectors in Case A, i.e., the short-period-wave case $(T=0.48 \mathrm{~s})$. Seabed configurations at the start and finish times of tracing colored pore water are also shown in full and broken lines, respectively.

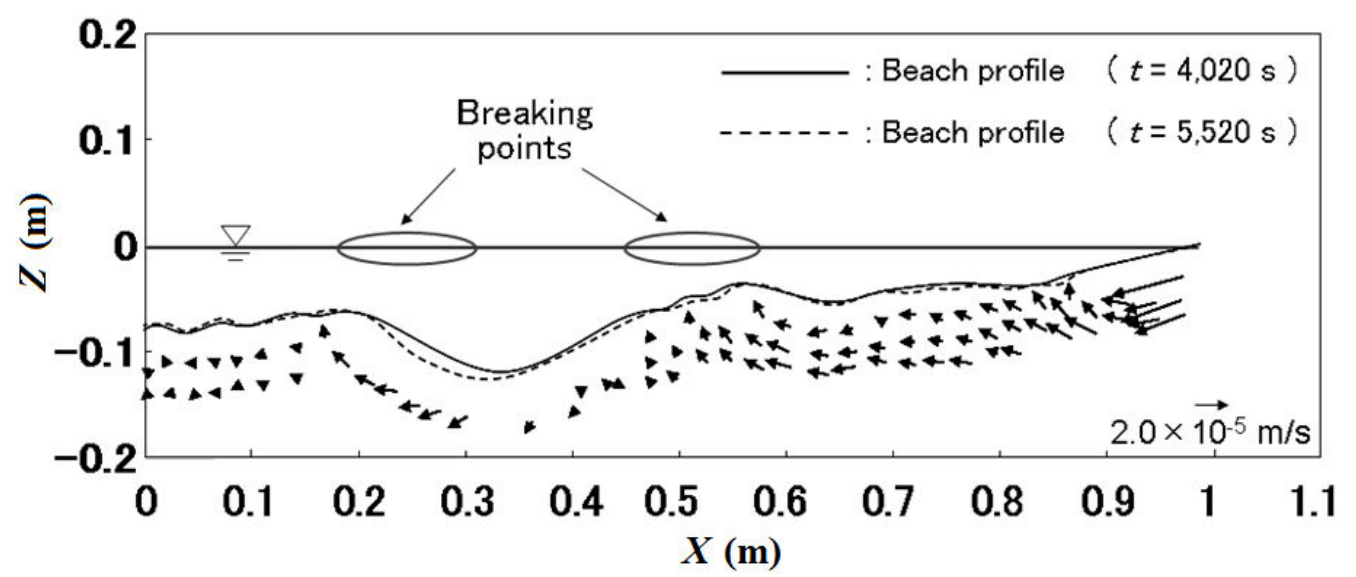

Figure 5. Seepage velocity vectors in Case B, i.e., the intermediate-period-wave case $(T=0.83 \mathrm{~s})$. Seabed configurations at the start and finish times of tracing colored pore water are also shown in full and broken lines, respectively.

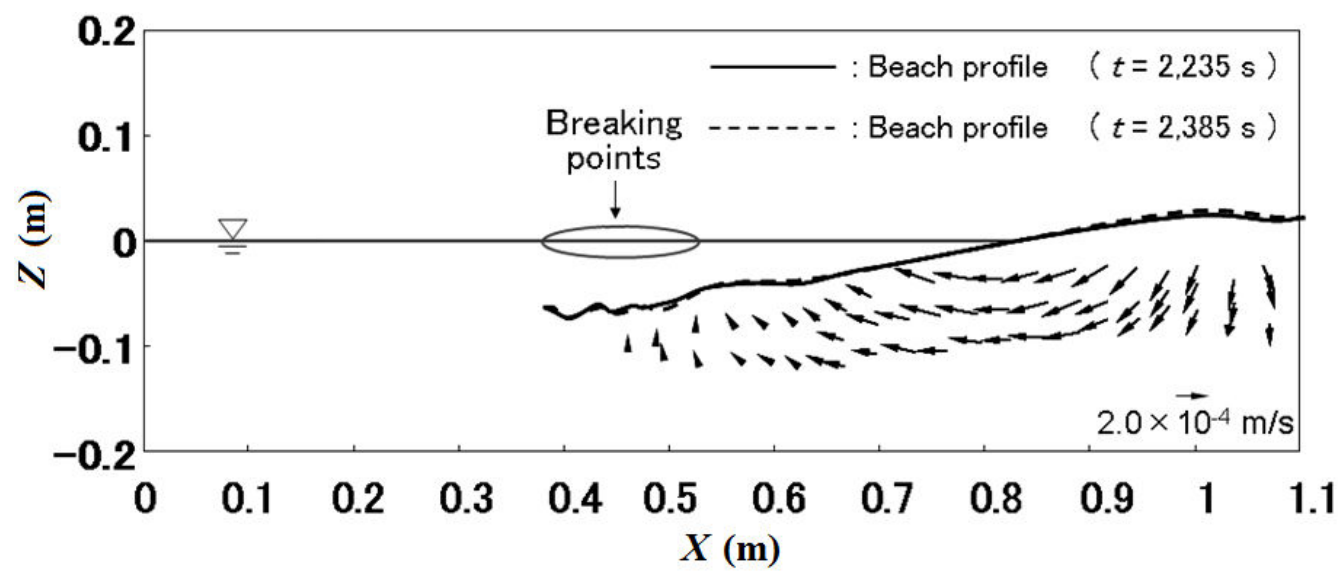

Figure 6. Seepage velocity vectors in Case C, i.e., the long-period-wave case $(T=1.20 \mathrm{~s})$. Seabed configurations at the start and finish times of tracing colored pore water are also shown in full and broken lines, respectively. 


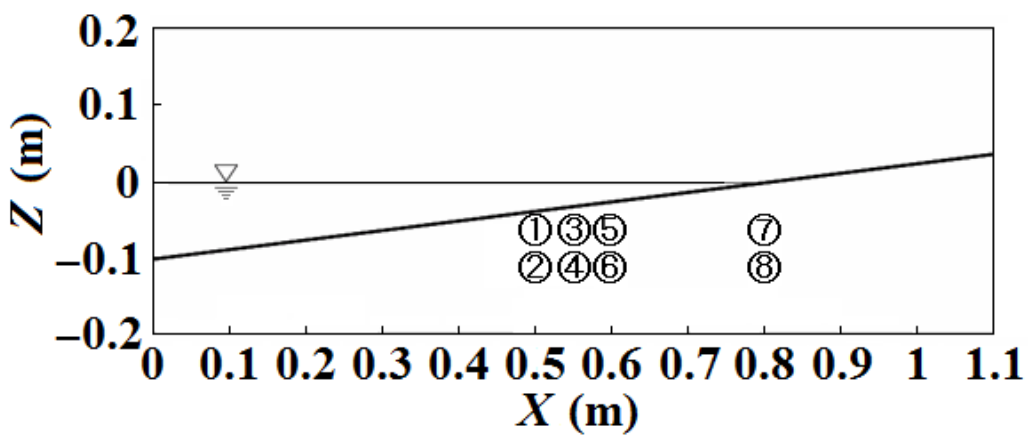

Figure 7. Positions of eight pressure gauges installed underground.

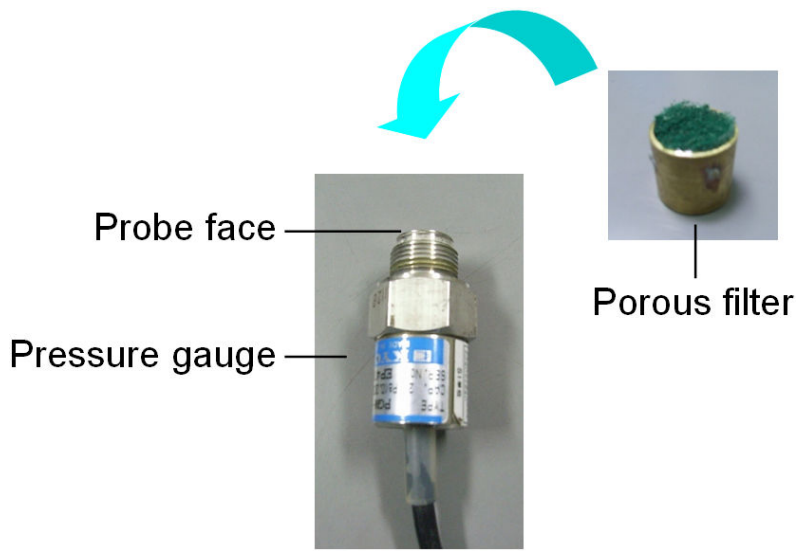

Figure 8. Pressure gauge. Its probe face was covered with a porous filter.

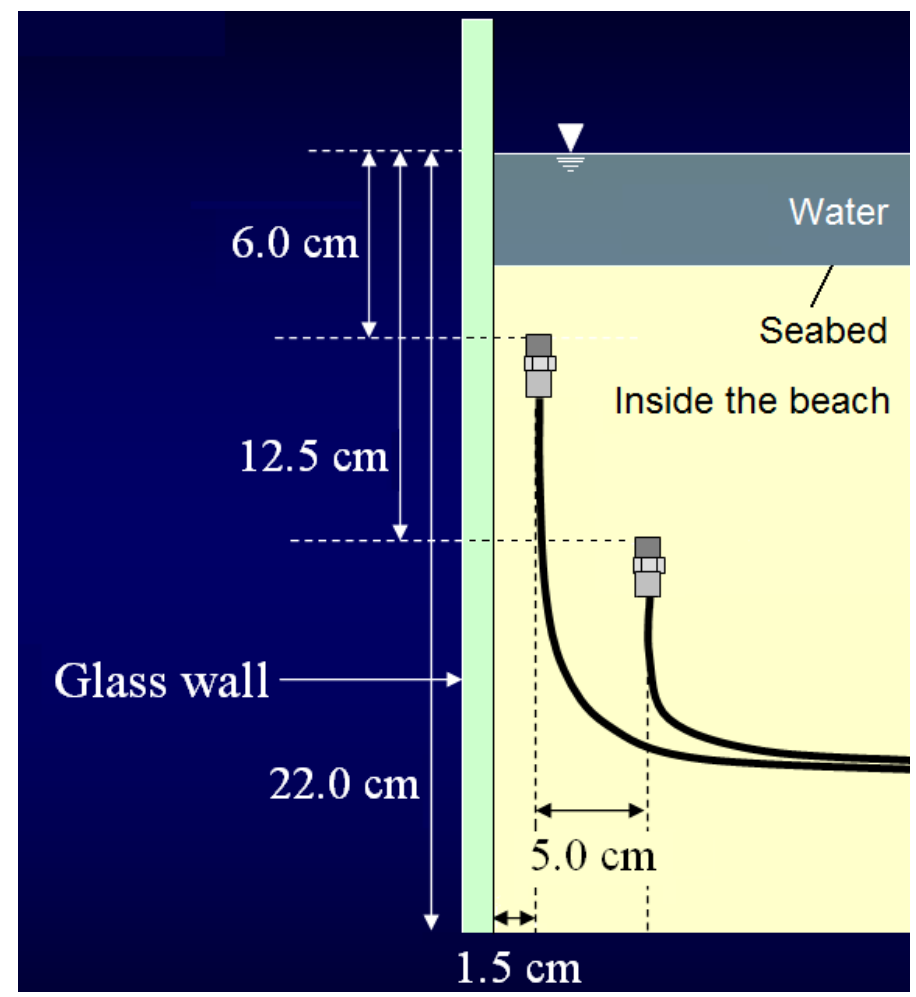

Figure 9. Setup of pressure gauges at the upper and lower positions. 

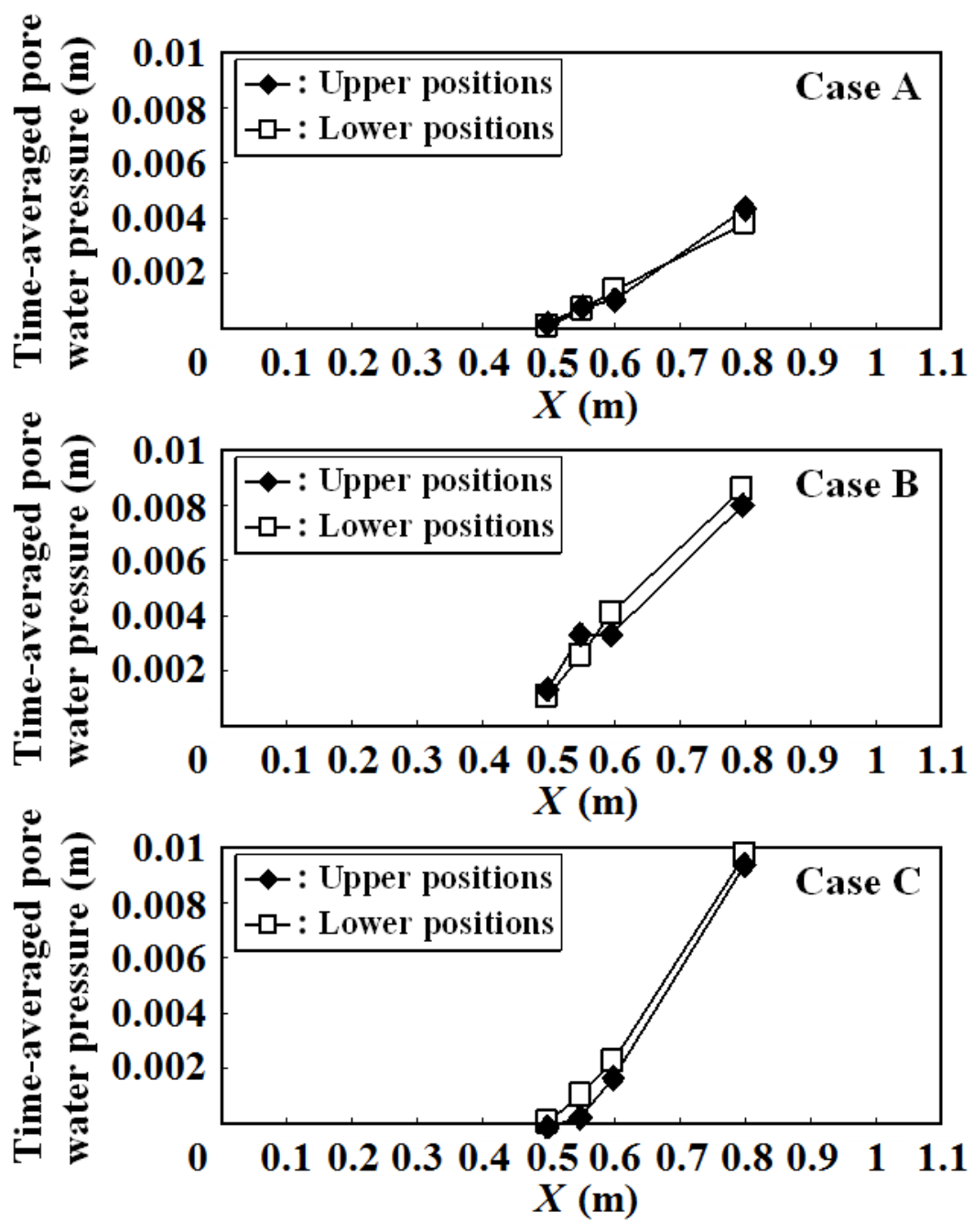

Figure 10. Time-averaged pore water pressures in Case A, B, and C. The pore water pressure is described by the displacement of the pore water pressure head from that in the still-water condition in the present paper.

According to Fig 10, the time-averaged pore water pressure was higher near the shoreline, resulting in the seepage flows generally towards offshore as shown in Figs. 4 - 6. As the incident-wave period was longer, the difference in pore water pressure between offshore and onshore points, where $X=0.5$ and $0.8 \mathrm{~m}$, respectively, was larger, so that the maximum value of time-averaged seepage velocity was larger as mentioned above.

In Case B, as shown in the second graph of Fig. 10, the time-averaged pore water pressure at the upper position was lower than that at the lower position on each $X$ where $0.58 \mathrm{~m} \leq X \leq 0.8 \mathrm{~m}$, resulting in time-averaged upward force acting on the pore water in this place; the reason is supposed that the absolute values of velocities in oscillatory flows over the seabed were comparatively large in the shallower water on the onshore side of the bars shown in Fig. 5, such that the time-averaged pore water pressure became lower near the seabed where $0.58 \mathrm{~m} \leq X \leq 0.8 \mathrm{~m}$.

In Case $\mathrm{C}$, where no bar was generated remarkably, the time-averaged pore water pressure was lower at the upper position than at the lower position on each $X$ where $0.5 \mathrm{~m} \leq X \leq 0.8 \mathrm{~m}$.

\section{Time Variation of Pore Water Pressure in a Breaker Zone}

Time variation of pore water pressure during a wave period is examined in Case C, i.e., the longperiod-wave case. In the discussion below, the original time when $t=0.0 \mathrm{~s}$ is fixed, although it is not the start time of experiment. 

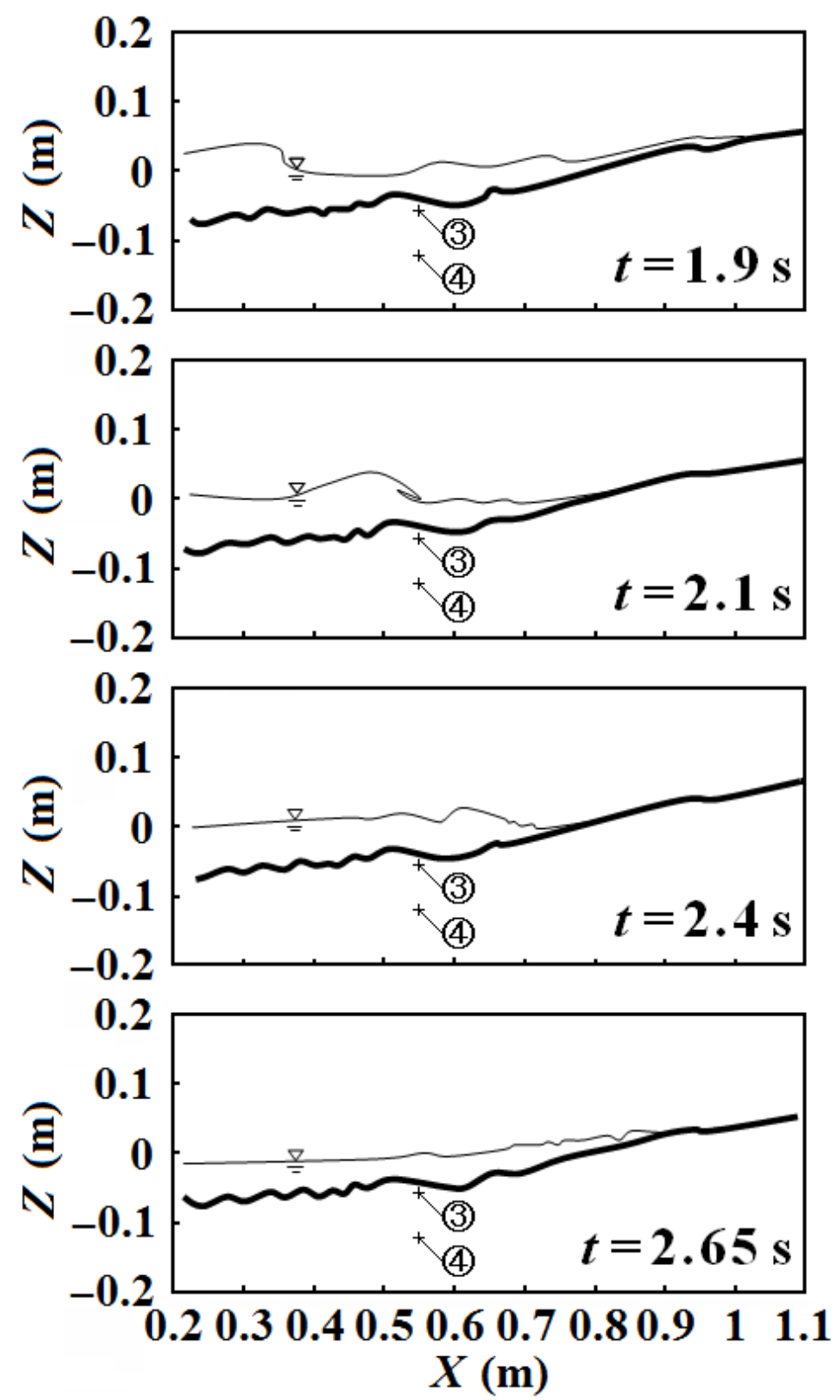

Figure 11. Time variations of water surface profile (thin line) and seabed configuration (thick line) in Case $\mathrm{C}$. The plunge of the breaker touched the water surface when $t=2.1 \mathrm{~s}$.

Time variation of water surface profile in Case $\mathrm{C}$ is shown in Fig. 11, as well as the seabed configuration. After the wave breaking, the wave showed a plunging-type breaker and the plunge touched the water surface in front of the wave when $t \cong 2.1 \mathrm{~s}$. According to a video image of sediment transport near the seabed, the plunge of breaker ran into the water pressing a water mass against the seabed during $2.3 \mathrm{~s} \leq t \leq 2.4 \mathrm{~s}$. A large-scale vortex, the axis of which was nearly horizontal, was generated under the water over the seabed due to the wave breaking when $t \cong 2.4 \mathrm{~s}$. The bore ran up over the slope and then the wave was going down towards offshore when $t \cong 2.65 \mathrm{~s}$.

Experimental data of pore water pressures measured using the pressure gauges of Channels 3 and 4 , where $X=0.55 \mathrm{~m}$, are shown in Fig. 12. As shown in the second chart of Fig. 11, the points denoted by the notation + , where the probe faces of Channels 3 and 4 were set, were below the plunging point. 


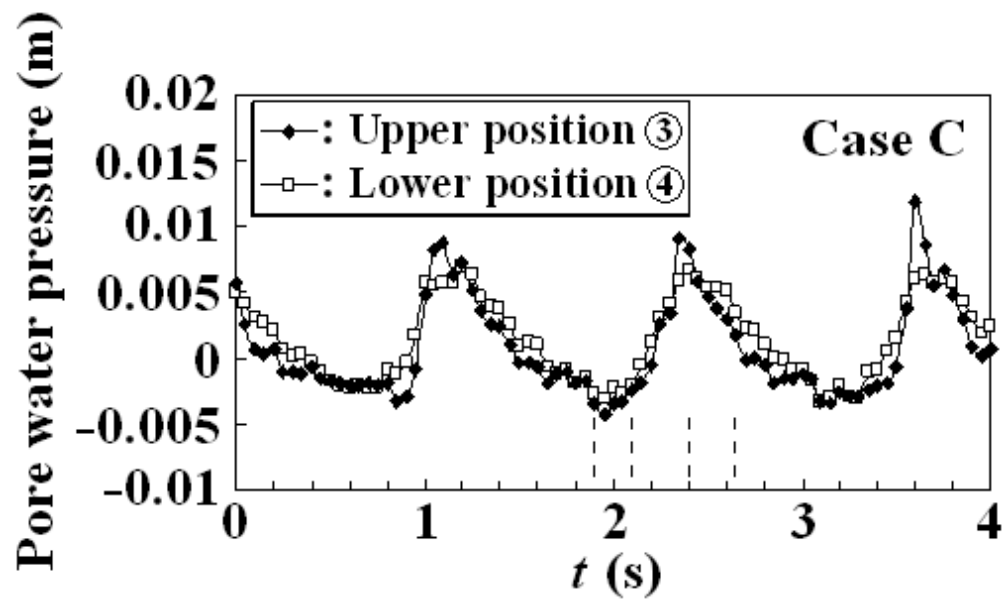

Figure 12. Time series of pore water pressures at the upper position (3) and lower position (4) in Case C.

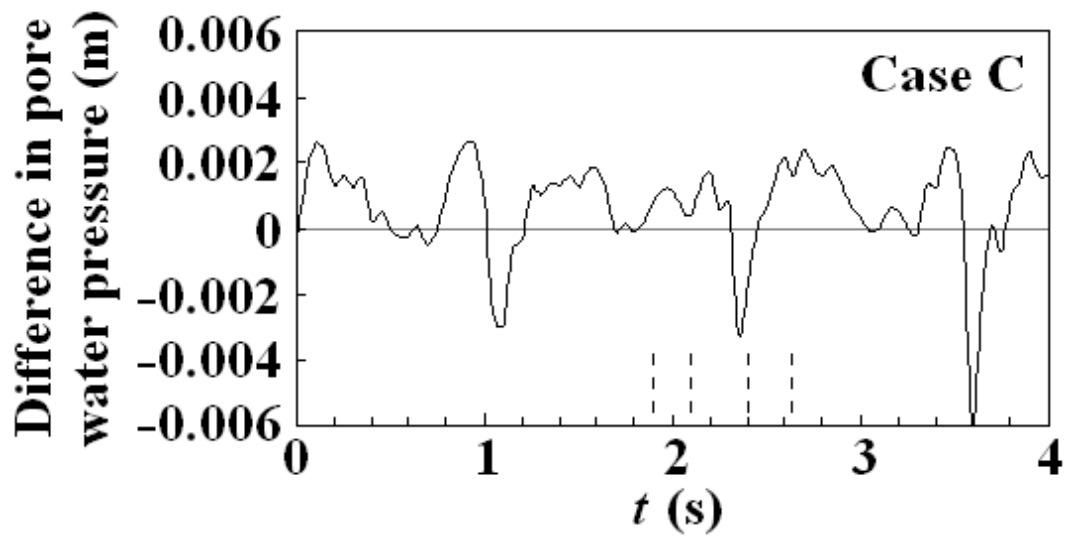

Figure 13. Time series of difference in pore water pressure, i.e., the pore water pressure at the lower position (4) minus that at the higher position (3), in Case C.

The times indicated by broken lines in Fig. 12 correspond to the times of the wave profiles shown in Fig. 11. Figure 12 does not show much difference in phase of pore water pressure between the upper and the lower positions, i.e., the positions (3) and (4), respectively, while the peak values of pore water pressure at the upper position (3) were larger than those at the lower position (4).

Figure 13 shows the difference in pore water pressure between the position (3) and the position (4) in Case $\mathrm{C}$, where the difference is determined by the pore water pressure at the lower position (4) minus that at the upper position (3). The times indicated by broken lines in Fig. 13 correspond to the times of the wave profiles shown in Fig. 11. The pore water pressure at the upper position (3) was larger than that at the lower position (4) during $2.3 \mathrm{~s} \leq t \leq 2.4 \mathrm{~s}$ due to the water body pressed against the seabed by the plunge of breaker as mentioned above, leading to downward force on the pore water to generate a downward seepage flow.

Time variation of constant-pore-water-pressure lines surrounded by the pressure gauges of Channels $1-8$ in Case $\mathrm{C}$ is evaluated approximately as shown in Fig. 14. In this domain, the pore water pressure in the onshore area was generally larger than that in the offshore area through $1.6 \mathrm{~s} \leq t \leq 2.8 \mathrm{~s}$.

When $t \cong 2.2 \mathrm{~s}$, however, the pore water pressure increased where $0.5 \mathrm{~m} \leq X \leq 0.58 \mathrm{~m}$ due to the wave propagation over the seabed, so that it became relatively low in an area where $X \approx 0.6 \mathrm{~m}$ to make concentration of seepage flows. As shown in Fig. 6, a bar, which was by no means large, was generated where $0.5 \mathrm{~m} \leq X \leq 0.63 \mathrm{~m}$; the area where the pore water pressure was locally low was located on the onshore side of the bar top below the bar. 

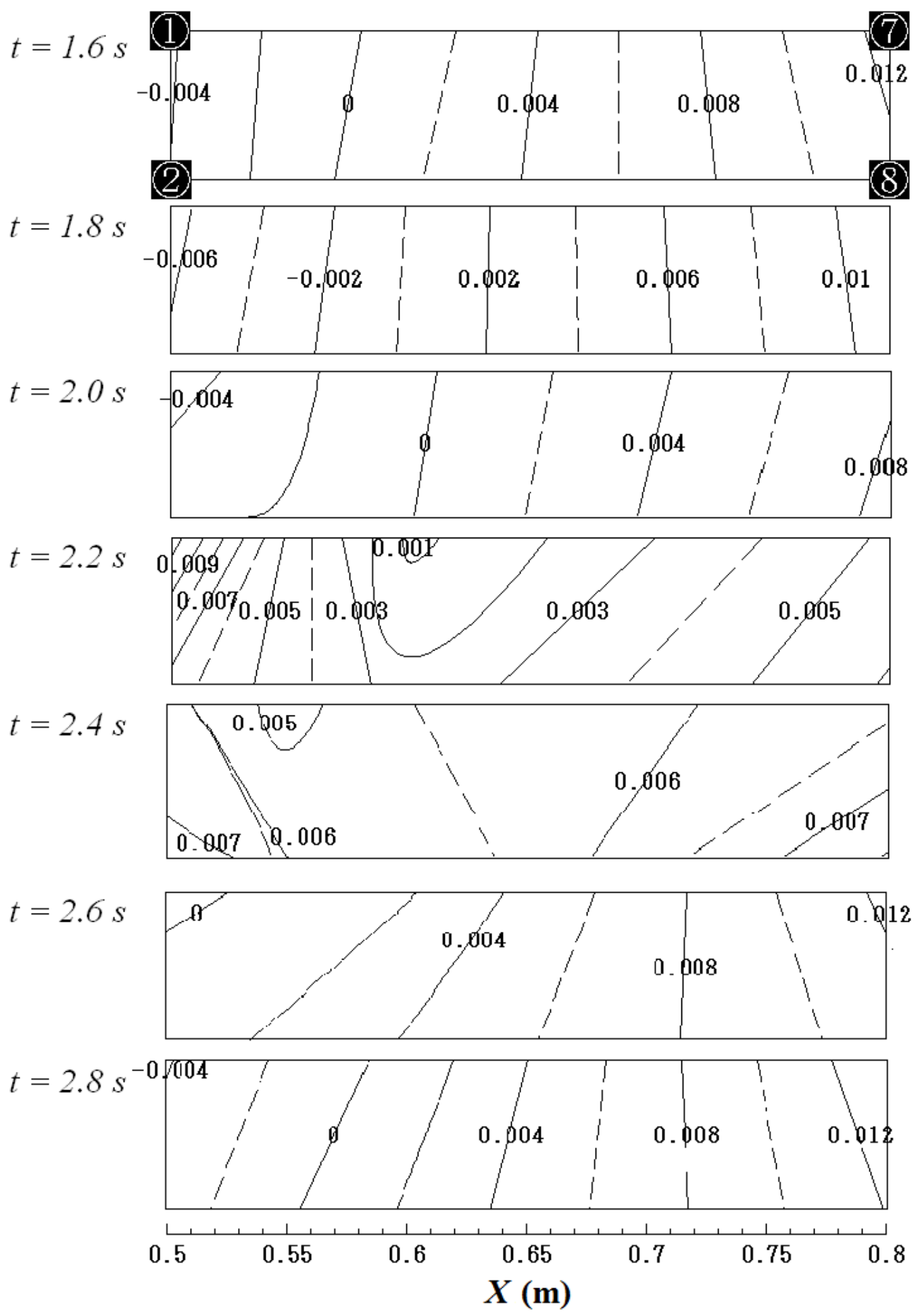

Figure 14. Time variation of constant-pore-water-pressure lines in Case $C$ (unit: $m$ ).

When $t=2.4 \mathrm{~s}$, the wave was propagating accompanied by a bore over the beach, in which the pore water pressure was rather uniform through the domain; then a backwash of the wave over the seabed caused underground upward force where $0.5 \mathrm{~m} \leq X \leq 0.7 \mathrm{~m}$ to generate an upward seepage flow when $t=2.6$ and $2.8 \mathrm{~s}$. 


\section{CONCLUSIONS}

Both the time-averaged seepage velocity vectors and the time-varying pore water pressures in the breaker zones were measured through the visualization of seepage flows with dye and the pressure gauges installed inside the beach built in the wave basin, respectively, in three cases of different incident-wave conditions. The time-averaged pore water pressure was higher near the shoreline, resulting in the seepage flows generally towards offshore. The longer the incident-wave period was, the larger the maximum value of time-averaged seepage velocity was. If a bar was generated remarkably, the pore water flowed out at the bar top or on the rather offshore side of the bar top. The pore water pressure in the breaker zone showed the time variation depending on the wave phases including wave breaking and bore propagation. There was a phase when the pore water pressure was locally low below the nearly onshore side of the bar top. The plunge of breaker pressed a water mass against the seabed, resulting in the downward force on the pore water to generate a downward seepage flow.

In consideration of effects of both time-averaged and time-varying phenomena including wave setup and wave breaking, respectively, further work is required to clarify the generation mechanism of seepage flows in breaker zones.

\section{ACKNOWLEDGMENTS}

Sincere gratitude is extended to Prof. Y. Kitamura, Kagoshima University, for his beneficial comments on measurement of pore water pressure.

\section{REFERENCES}

Cheong, C., H. Kang, S. Park, D. Ra, and M. Okada. 2002. Penetration of spilled fuel oil C and its influence on the seawater infiltration into sandy beach sediments, Environ. Eng. Res., 7, 169-175.

Inouchi, K., Y. Kishi, and T. Kakinuma. 1990. The motion of coastal groundwater in response to the tide, J. Hydrol., 115, 165-191.

Kudella, M. and H. Oumeraci. 2006. Development of residual pore pressure in the sand bed beneath a caisson breakwater, Proceedings of $30^{\text {th }}$ International Conference on Coastal Engineering, ASCE, 4554-4566.

Ma, H., N. Mizutani, S. Eguchi, and D. Hur. 2004. Study on beach profile change and wave induced velocity field in permeable beach, Annual Journal of Civil Engineering in the Ocean, JSCE, 20, 509-514. (in Japanese)

Mutsuda, H., Y. Doi, S. Morikawa, and R. Miake. 2001. Relationship between wave induced percolation mechanism and breaker types in the surf zone, Journal of Coastal Engineering, JSCE, 48, 1206-1210. (in Japanese)

Precht, E. and M. Huettel. 2004. Rapid wave driven advective pore water exchange in a permeable coastal sediment, J. Sea Res., 51, 93-107. 